\title{
PARTIAL SEQUENCE ANALYSIS OF MITOCHONDRIAL CYTOCHROME B GENE OF Labeo calbasu OF BANGLADESH
}

\author{
Begum, R. A., M. T. Alam, H. Jahan and M. S. Alam \\ Genetics and Molecular Biology Laboratory, Department of Zoology, University of Dhaka, Dhaka- \\ 1000, Bangladesh
}

\begin{abstract}
Labeo calbasu (Family Cyprinidae) was studied at DNA level to know genetic diversity within and between species. The mitochondrial cytochrome $b(c y t-b)$ gene of $L$. calbasu was sequenced and compared to the corresponding sequences of other Labeo species. DNA was isolated from the tissue sample of $L$. calbasu using phenol: chloroform extraction method. Forward and reverse primers were designed to amplify the target region of cytochrome $b$ gene. A standard PCR protocol was used for the amplification of the desired region. Then, the forward and reverse sequences obtained were aligned and edited to finalize a length of 510 nucleotides which was submitted to NCBI genbank database. Nucleotide BLAST of this sequence at NCBI resulted $100 \%$ sequence similarity with $L$. calbasu sequence of the same region of cyt-b gene. Multiple sequence alignment of the sequence with seven more Labeo species sequences revealed 120 polymorphic sites, which have been mark of diversity among the species and might be used in molecular identification of the Labeo species. A constructed phylogenetic tree has shown relationship among the Labeo species. This research demonstrated the usefulness of mitochondrial DNA-based approach in species identification. Further, the data will provide appropriate background for studying genetic diversity within-species of the Labeo species in general and of $L$. calbasu in particular.
\end{abstract}

Key words: Cytochrome $b$ gene; Mitochondrial DNA; Nucleotide polymorphism; Labeo calbasu.

\section{INTRODUCTION}

The freshwater habitats of Bangladesh are very rich. There are about 260 freshwater fish species in Bangladesh (IUCN Bangladesh 2015). Labeo, is a genus of fish belonging to the family Cyprinidae of the order Cypriniformes and found in the tropical countries of the world especially in the Indian subcontinent. Cyprinidae is the largest among the vertebrate families and also the largest fish family. Ten Labeo species are reported from Bangladesh (IUCN Bangladesh 2015). Among them, Labeo calbasu has the highest demand because of its delicacy.

The water bodies of Bangladesh are being polluted by agricultural chemicals and industrial effluents continuously making the fish habitats more stressful. There are evidences that a total of 30 riverine finfish species has already been extinct from Bangladesh (Hossain 2014). Species diversity and genetic diversity (i.e. species number and population size) have significantly reduced in Bangladeshi aquatic habitats (Chaki et al. 2014, Joadder et al. 2015, Mohsin et al. 2014). Similarly, the abundance of $L$. calbasu is affected by the environment. Its number is decreasing day by day in the habitats which might cause loss of genetic diversity within population. Since, small populations are vulnerable to the loss of genetic diversity, the study of $L$. calbasu at genetic level is very important. From this perspective, molecular identification through mitochondrial gene sequence is a starting point toward studying the species more intensively.

Mitochondria is a cell organelle that harbors a circular DNA molecule of around 16KB possessing 37 genes. The sequences of the mitochondrial genes are successfully used in species identification. Among them, the use of cytochrome oxidase I (COI) is very common (Hebert et al. 2003). However, $C O I$ sequence is not always sufficient to resolve the taxonomic uncertainties of closely related species, especially those of the same genus. So, other genes of the mitochondrial genome, such as cytochrome $b$ (cyt-b), 16SrRNA, 12SrRNA, ND1,ND2 and D-loop region, are often used in molecular identification to 
remove any unambiguity. $C y t-b$ gene is a protein coding gene producing cytochrome $\mathrm{b}$ that is essential for mitochondrial functioning. It is located in between tRNA ${ }^{\text {glu }}$ and RRNA $^{\text {thr }}$ in the mitochondrial genome (Fig. 1).

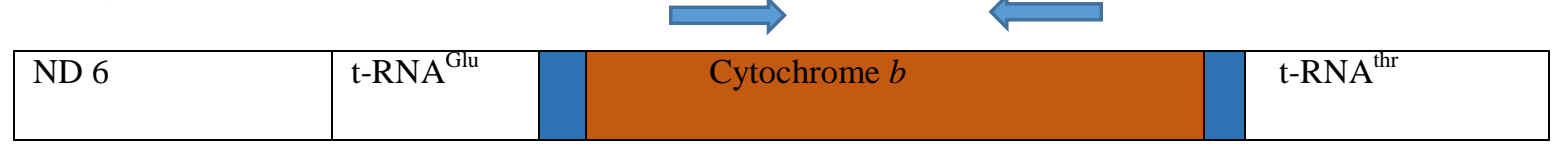

Fig. 1. Schematic diagram of Cytochrome $b$ gene showing its position in mitochondrial genome.

It is approximately one thousand base pair long. The structure and function of cytochrome b is wellknown (Esposti et al. 1993). The nucleotide sequence of the $c y t$ - $b$ gene has species-specificity and used in evolutionary studies and forensic investigations (Kocher et al. 1989, Smith and Patton 1991). The cyt$b$ gene sequence of $L$. calbasu from India is available in the NCBI genbank database (Accession no. KF574601). But, a complete sequence of $c y t-b$ gene of $L$. calbasu of Bangladesh has not been reported yet. Due to geographically separate habitats, there might have differences in the gene sequences of the same species which could be a measure of genetic diversity. So, the $c y t-b$ gene of $L$. calbasu from Bangladesh needs to be sequenced. Therefore, the main objective of the present study was to decipher $c y t-b$ gene sequence of a local sample of L. calbasu from Bangladesh and compare it to that from India. In addition, cyt$b$ sequence of $L$. calbasu was also compared to that of other species available in the genbank database.

\section{MATERIAL AND METHODS}

Labeo calbasu sample was collected from local market of Mymensingh city, Bangladesh. The sample was placed in ice immediately after collection and transferred to laboratory for further studies. After morphometric analysis, tissue sample was collected from the dorsal portion of the body. Approximately $45 \mathrm{mg}$ of soft muscle tissue were collected for the extraction of DNA and rest was preserved as voucher specimen. Total genomic DNA was extracted by using phenol: chloroform extraction method with slight modification (Begum et al. 2004). The extracted DNA was then visualized in $1.5 \%$ agarose gel of a low melting point grade at $120 \mathrm{~V}$ for 20 minutes. The extracted DNA samples were run in the agarose gel, along with a loading dye (Bromophenol blue) in a 5:1 ratio.

A region of cytochrome-b gene (target size around 650bp) was amplified by polymerase chain reaction (PCR). The chemicals used for the amplification of mitochondrial DNA were $2 \mu 1$ of 10X PCR reaction buffer, $1.6 \mu \mathrm{l}$ of $25 \mathrm{mM} \mathrm{MgCl}, 0.5 \mu \mathrm{l}$ of $10 \mathrm{mM}$ dNTP, $0.5 \mu \mathrm{l}$ of $c y t$ - $b$ forward primer, $0.5 \mu 1$ of $c y t$ - $b$ reverse primer, $0.16 \mu 1$ of Taq DNA polymerase, $2 \mu 1$ Template DNA, and sterilized distilled water up to a total volume of $25 \mu \mathrm{l}$. The forward and reverse primers designed to amplify a region of the cyt- $b$ gene were 5'- GCA ACA TAC ACG CCA ACG G -3' and 5'- TGA GGT GTG TAG GAG GGG TA $3^{\prime}$, respectively. Amplifying conditions were $94^{\circ} \mathrm{C}$ for $60 \mathrm{~s}$ in denaturation, $53^{\circ} \mathrm{C}$ for $30 \mathrm{~s}$ in annealing, and $72^{\circ} \mathrm{C}$ for $30 \mathrm{~s}$ in extension for 30 cycles with a final polymerization step at $72^{\circ} \mathrm{C}$ for five minutes. PCR products were visualized using agarose gel electrophoresis. The PCR products of interest were then purified using Favor Prep PCR Clean up Mini Kit (Favorgen Biotech Corp.). After purification, the PCR product was sequenced in both directions by a sequencing service provider (Macrogen Inc., Korea). The nucleotide sequence of $c y t-b$ gene obtained from the present study was subjected to NCBI BLASTn and then submitted to the GenBank database. The $c y t$ - $b$ gene sequences of eight selected Labeo species were collected from NCBI nucleotide database for intraspecific and interspecific comparison. The accession numbers of the sequences used were AP011329 (L. angra), KF574952 (L. bata), NC_026217 (L. boggut), MG010391 (L. calbasu of the present study), KF574601 (L. calbasu India), NC_026217 (L. fimbriatus), KT001152 (L. gonius), AP013340 (L. pangusia), KF574619 (L. rohita) and NC_001887 (Balanoglossus carnosus as outgroup). Multiple sequence alignment and neighbor-joining phylogenetic tree were constructed using SEAVIEW software (Gouy et al. 2010). The multiple sequence alignment 
allowed to study the number of polymorphic sites, and thus the phylogenetic relationships among different Labeo species based on the $c y t-b$ gene sequence was investigated.

\section{RESULTS AND DISCUSSION}

The image of the extracted DNA ran in 1\% agarose gel has been presented in Fig. 2a. The isolated DNA has appeared to be of around 10kb size as it occurs in such cases. The PCR product sent for sequencing checked by running in gel has been presented in Fig. $2 \mathrm{~b}$.

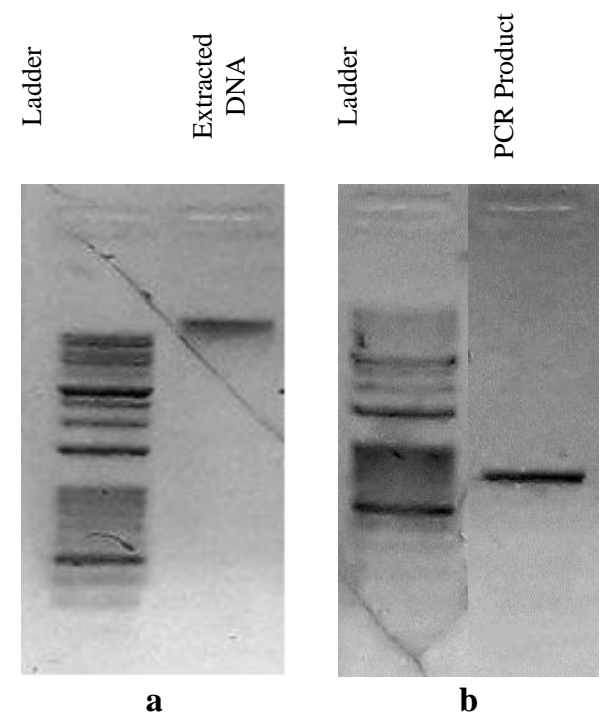

Fig. 2. a. The images of agarose gel electrophoresis for the extracted DNA of Labeo calbasu; and b. Cytochrome $b$ primer based PCR product.

The size of the amplified product appeared to be between 600 and 700bp indicating proper priming during polymerase chain reaction process. The nucleotide sequence of the amplified region of the $c y t-b$ gene of $L$. calbasu has been presented in Fig. 3. Though the size of the targeted PCR product was around $650 \mathrm{bp}$, small regions of the two ends were omitted from further analysis due to common sequencing errors clearly detectable from chromatograms. Thus, a corrected sequence of 510bp was finalized for further study and submitted to genbank database. The accession number given to the sequence submitted to NCBI database is MG010391.1.

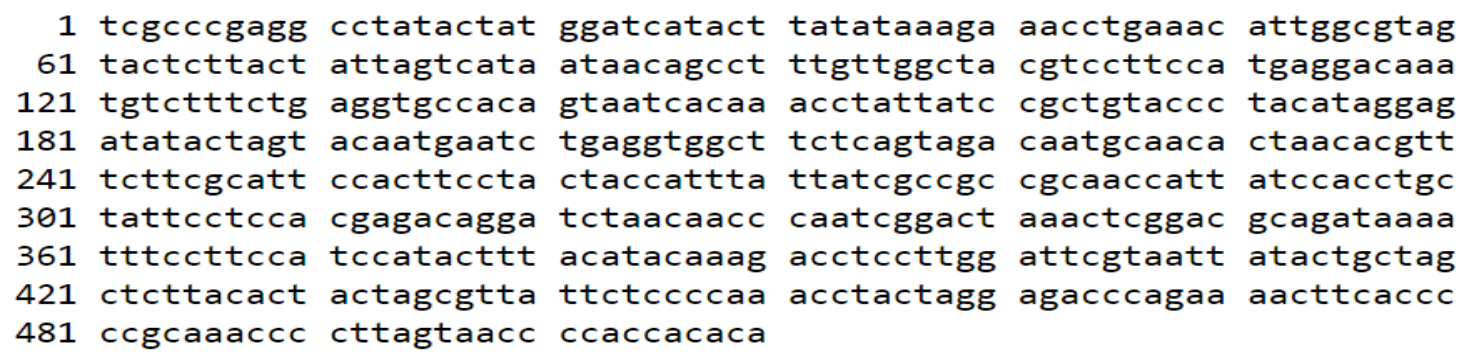

Fig. 3. The partial sequence (510bp) of cytochrome $b$ gene of $L$. calbasu from Bangladesh

The BLAST results of the sequenced region brought $L$. calbasu as topmost hit with $100 \%$ similarity confirmed the taxonomy of the organism (Fig. 4). The available $c y t$ - $b$ sequence of $L$. calbasu from India had $100 \%$ identity with the $c y t-b$ sequenced regions of the present study. In other words, no polymorphic 
site was detected when corresponding regions of the $c y t-b$ gene of $L$. calbasu from Bangladesh and India were aligned. Thus, this result indicated high sequence conservation in between two individuals of the same species studied from different geographical locations.

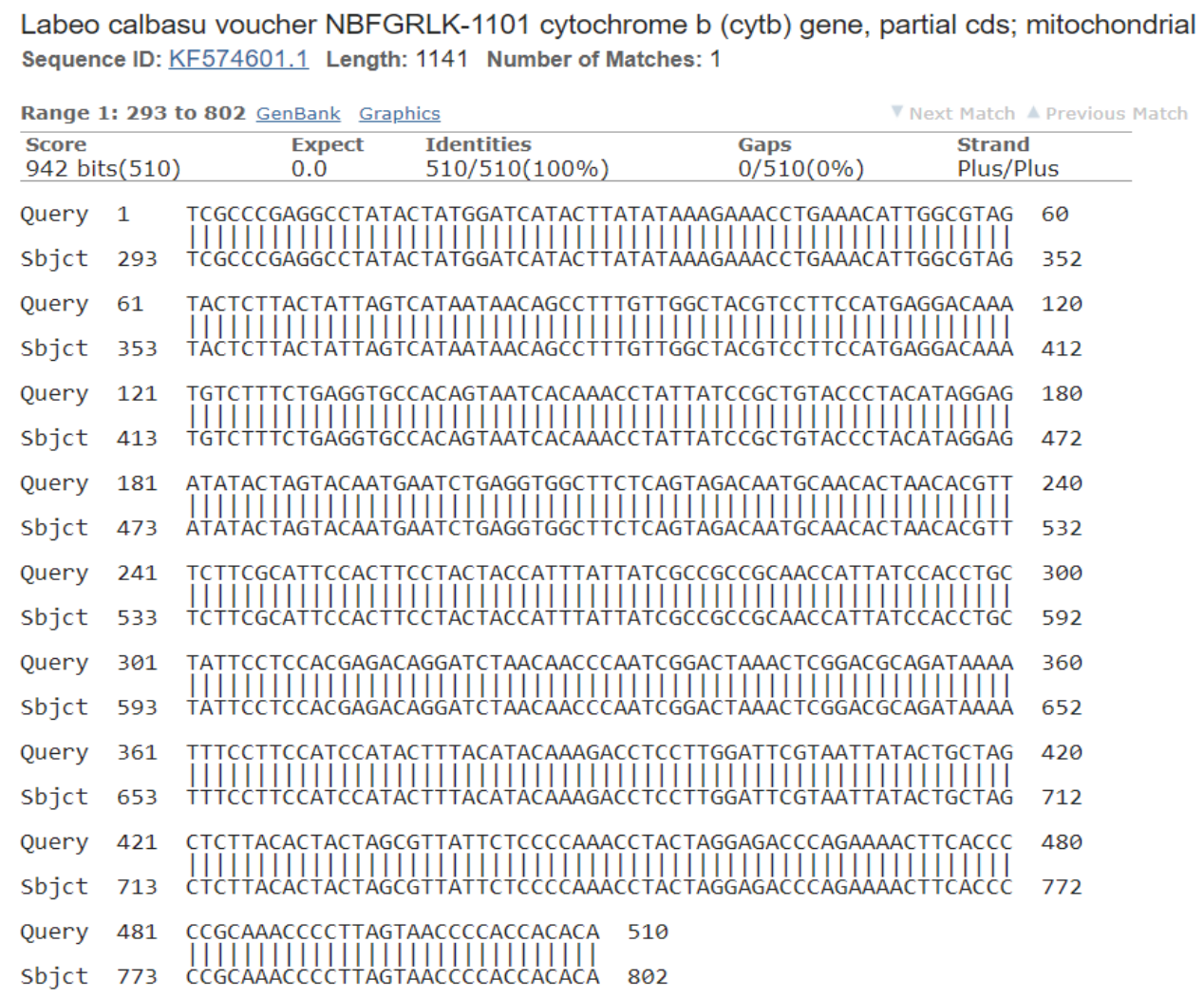

Fig. 4. The cytochrome $b$ gene sequence (partial, 510bp) of Labeo calbasu from Bangladesh showing $100 \%$ similar identity with that of the same species from India. Image taken from NCBI BLAST search result.

Multiple sequence alignment involving total eight Labeo species (viz. L. angra, L. bata, L. boggut, L. calbasu, L. fimbriatus, L. gonius, L. pangusia and L. rohita) showed variations in the corresponding regions among the species (Fig. 5). Out of 510 nucleotides in the sequence, there were total 120 polymorphic sites. These polymorphic sites could be used as the markers of Labeo species identification through PCR-sequencing. In molecular identification, mitochondrial COI, 16SrRNA, 12SrRNA and cyt-b are used frequently. Jahan et al. (2017) have studied 16SrRNA gene sequence of three Labeo species viz., L. rohita, L. bata and L. gonius and found 23 polymorphic sites (5.8\%) in 396 nucleotide long sequence. The polymorphic site variations (23.5\%) are more frequent than that reported by Jahan et al. (2017) because of larger size sequences, higher number of species (eight) and use of different region of mitochondrial genome (part of $c y t-b$ ) in the present study.

The GC content of the sequenced region of L. calbasu is $43.33 \%$. Similarly, the GC contents of the corresponding $c y t-b$ gene fragment of the available Labeo species are $43.33 \%$ in $L$. angra, $43.73 \%$ in $L$. bata, $42.75 \%$ in L. boggut, $44.51 \%$ in L. fimbriatus, $44.51 \%$ in L. gonius, $42.35 \%$ in L. pangusia, and $44.31 \%$ in L. rohita. Though the GC content of the cyt-b gene region of $L$. calbasu does not differ with that of L. angra, there are variations in the nucleotide sequence among these two species (Fig. 5). On the other hand, GC contents in L. fimbriatus and L. gonius do not differ and their nucleotide sequences also do not differ which could be a sign of very close relationship among these two species. 


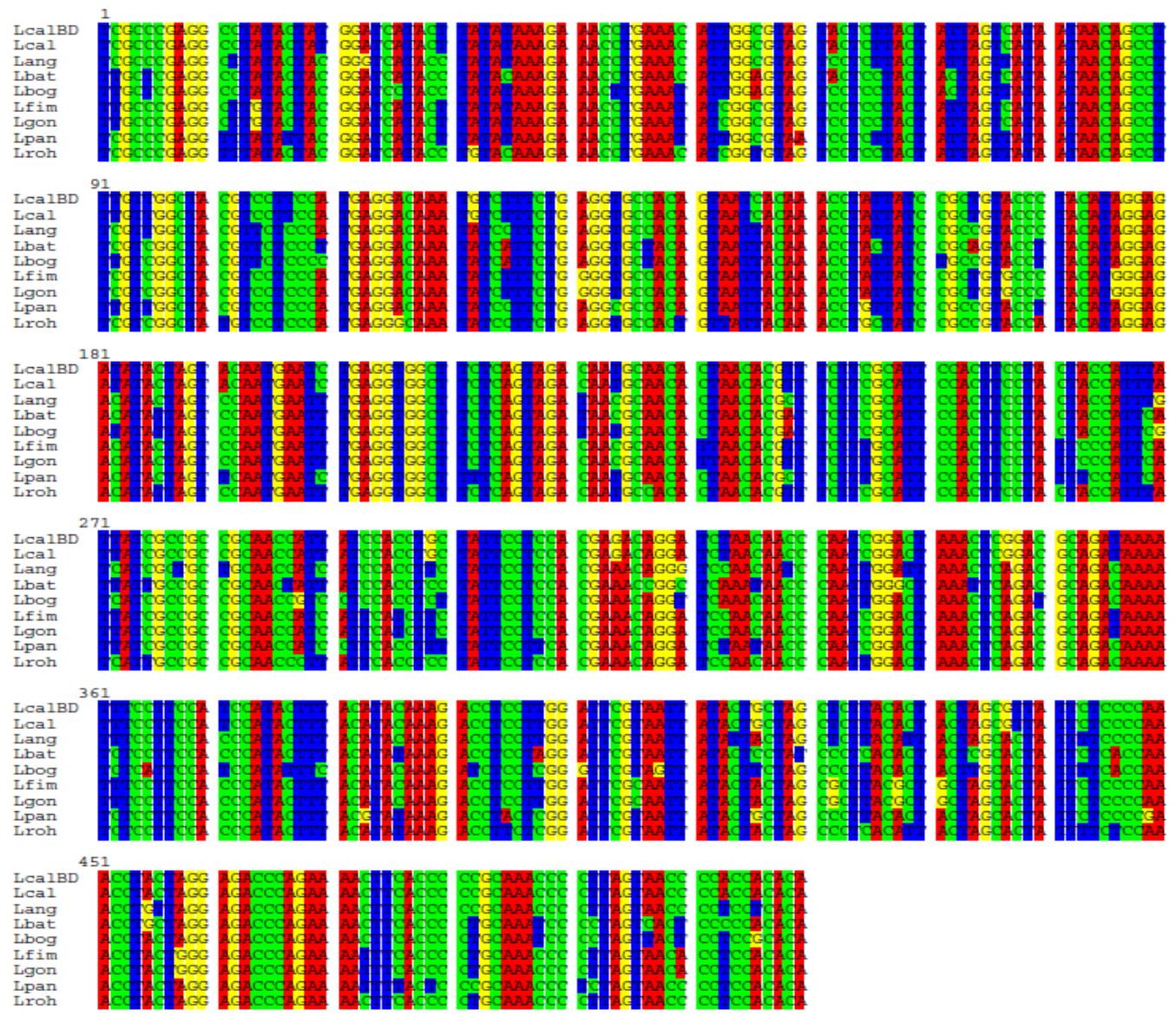

Fig. 5. The multiple sequence alignment of the orthologous regions of cytochrome b gene showing sequence diversity among different species under the genus Labeo. Total eight Labeo species have been compared. These are $L$. calbasu (LcalBD represents present study and Lcal, India), L. angra (Lang), L. bata (Lbat), L. boggut (Lbog), L. fimbriatus (Lfim), L. gonius (Lgon), L. pangusia (Lpan) and L. rohita (Lroh).

The neighbor-joining phylogenetic tree constructed with 100 bootstrap values have been presented in Fig. 6. A hemichordate, Balanoglossus carnosus, was chosen as out group.

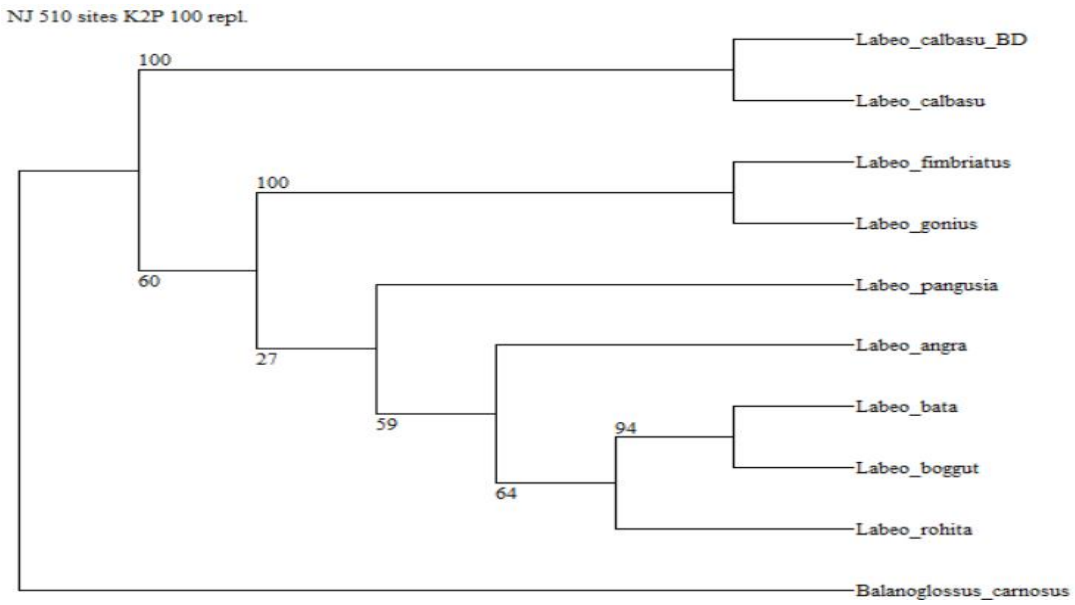

Fig. 6. Relationship among Labeo species based on $c y t-b$ gene sequence. Phylogenetic tree has been constructed using neighbor-joining method with 100 bootstrap values. L. calbasu Bangladesh represents the $c y t-b$ gene sequence of the present study. A hemichordate Balanoglossus carnosus has been selected as outgroup. 
In the tree, two sequences of L. calbasu (Bangladesh and India) formed a separate group indicating distinctiveness of this species from all other Labeo species of present study. On the other hand, $L$. fimbriatus and L. gonius were in the same group. Though these are two different species, they showed monophyly due to highly conserved sequences of $c y t-b$ gene regions. Again, L. bata and L. boggut created a monophyletic group with the same origin indicating their close relationship. The similar relationship of L. bata and L. boggut have been reported by Yang et al. (2012) who studied the molecular phylogeny of the cyprinid tribe Labeonini extensively. L. rohita and L. calbasu formed separate clade as presented by Yang et al. (2012) that also conforms the result of the present study.

The sequence variations reflected in multiple sequence alignment and phylogenetic tree have significance in understanding the relationships among the Labeo species and molecular identification of the species through PCR-sequencing or RFLP (restriction fragment length polymorphism) analysis.Besides, species-specific primers can be designed from the sequence analysis to identify the species effectively with less cost. Furthermore, the $c y t-b$ gene of other Labeo species of Bangladesh also needs to be sequenced like $L$. calbasu to have data of the local species.

\section{REFERENCES}

Begum, R. A., T. Yamaguchi and W. Shugo. 2004. Molecular phylogeny of thoracican barnacles based on the mitochondrial 12S and 16S rRNA genes. Sessile Organisms. 21(2): 47-54.

Chaki, N., S. Jahan, M. F. H. Fahad, S. M. Galib and A. B. M. Mohsin. 2014. Environment and fish fauna of the Atrai River: global and local conservation perspective. J. Fish. 2(3): 163-172.

Esposti, D. M., S. D. Vries, M. Crimi, A. Ghelli, T. Paternello and A. Meyer. 1993. Mitochondrial cytochrome-b: evolution and structure of the protein. Biochim. Biophys. Acta. 1143: 243-271.

Gouy, M., S. Guindon and O. Gascuel. 2010. SeaView version 4: a multiplatform graphical user interface for sequence alignment and phylogenetic tree building. Mol. Biol. Evol. 27(2): 221-224.

Hebert, P. D., S. Ratnasingham, J. R. deWaard. 2003. Barcoding animal life: Cytochrome c oxidase subunit divergences among closely related species. Proc. Biol. Sci. 270:S96-9.

Hossain, M. A. R. 2014. Habitat and fish diversity: Bangladesh Perspective. In: Advances in Fisheries Research in Bangladesh, I. Wahab MA, Shah MS, Hossain MAR, Barman BK and Hoq ME (eds). Proceedings of Fifth Biennial Fisheries Conference and Research Fair 2012. 18-19 January 2012. Bangladesh Agricultural Research Council, Dhaka. Bangladesh Fisheries Research Forum, Dhaka, Bangladesh. 246 pp.

IUCN Bangladesh. 2015. Red List of Bangladesh. Volume 5: Freshwater Fishes. IUCN, International Union for Conservation of Nature, Bangladesh Country Office, Dhaka, Bangladesh. 360 pp.

Jahan H., M. Akter, R. A. Begum, R. M. Shahjahan. 2017. Identification and comparison of three carp fishes based on mitochondrial 16S rRNA gene. Dhaka Univ. J. Biol. Sci. 26 (2): 167-174.

Joadder, M. A. R., S. M. Galib, S. M. M. Haque and N. Chaki. 2015. Fishes of the river Padma, Bangladesh: Current trend and conservation status. J. Fish. 3(2): 259-266.

Kocher, T. D., W. K. Thomas, A. Meyer, S. V. Edwards, S. Pääbo, F. X. Villablanca and A. C. Wilson. 1989. Dynamics of mitochondrial DNA evolution in animals: amplification and sequencing with conserved primers. Proc. Natl. Acad. Sci. 86: 6196-6200.

Mohsin, A. B. M., F. Yeasmin, S. M. Galib, B. Alam and S. M. M. Haque. 2014. Fish fauna of the Andharmanik River in Patuakhali, Bangladesh. Middle-East J. Sci. Res. 21(5): 802-807.

Smith, M. F. and J. L. Patton. 1991. Variation in mitochondrial cytochrome $b$ sequence in natural populations of South American akodontine rodents (Muridae: Sigmodontinae). Mol. Biol. Evol. 8: 85-103.

Yang, L., M. Arunachalm, T. Sado and B. Levin. 2012. Molecular phylogeny of the cyprinid tribe Labeonini (Teleostei: Cypriniformes). Mol. Phyl. Evo. 65: 362-379. 